\title{
Dietary values of astaxanthin and canthaxanthin in Penaeus monodon in the presence and absence of cholesterol supplementation: effect on growth, nutrient digestibility and tissue carotenoid composition
}

\author{
Jin Niu ${ }^{1}$, Chun-Hou $\mathrm{Li}^{1}$, Yong-Jian Liu ${ }^{2}$, Li-Xia Tian ${ }^{2}$, Xu Chen ${ }^{1}$, Zhong Huang ${ }^{1}$ and Hei-Zhao Lin ${ }^{1}$ * \\ ${ }^{1}$ Aquaculture and Biotechnology Division, South China Sea Fisheries Research Institute, Chinese Academy of Fishery \\ Sciences, Guangzhou 510300, People's Republic of China \\ ${ }^{2}$ Nutrition Laboratory, Institute of Aquatic Economic Animals, School of Life Science, Sun Yat-sen University, Guangzhou, \\ People's Republic of China
}

(Submitted 19 April 2011 - Final revision received 2 September 2011 - Accepted 2 September 2011 - First published online 6 December 2011)

\begin{abstract}
Penaeus monodon (mean initial wet weight 1.19 (SE 0.01) g) were fed seven diets in triplicate: a control diet (D1) without carotenoids; three diets formulated to supply $0 \cdot 1 \%$ astaxanthin alone (D2), $0 \cdot 2 \%$ astaxanthin alone (D3), and a combination of $0 \cdot 1 \%$ astaxanthin and $1 \%$ cholesterol (D4); three diets with $0.07 \%$ canthaxanthin alone (D5), $0.13 \%$ canthaxanthin alone (D6), and a combination of $0.07 \%$ canthaxanthin and $1 \%$ cholesterol (D7). Weight gain (WG, \%), specific growth rate (SGR, \%/d) and survival were chosen as parameters of shrimp growth performance. Total antioxidant status (TAS), superoxide dismutase (SOD), aspartate aminotransferase (AST) and alanine aminotransferase (ALT) were chosen as indices of shrimp plasma antioxidant capacity. Meanwhile, digestibility, retention efficiency and tissue carotenoids were also investigated to determine the additive effect of cholesterol on the efficiency of astaxanthin and canthaxanthin. After $74 \mathrm{~d}$ rearing, WG and SGR of shrimp fed D2-D4 and D7 were higher than those of shrimp fed D1 $(P<0 \cdot 05)$. Shrimp fed D4 had the highest survival. The apparent digestibility coefficients (ADC) of astaxanthin in D2-D4 were higher than those of canthaxanthin in D5-D7 $(P<0.05)$. Although ADC of astaxanthin were quite high $(>98 \%)$ in D2-D4 and no differences were found among them $(P>0.05)$, the carotenoid retention efficiencies in the whole body, muscle and shell (D2-D3 treatments) were considerably low; however, cholesterol supplementation significantly improved the carotenoid retention efficiencies in the whole body, muscle and shell (D4 treatment). Accordingly, the addition of cholesterol also significantly enhanced the carotenoid contents of tissues. Shrimp fed supplemented carotenoid diets (D2-D7) had higher TAS and lower SOD, ALT and AST than shrimp fed D1 $(P<0 \cdot 05)$. A low dissolved oxygen stress test was conducted for $7 \mathrm{~d}$ after the rearing trial and shrimp survival was also compared among the treatments. The survival of shrimp fed the diets supplemented with astaxanthin or canthaxanthin was higher than that of shrimp fed D1 during the stress test $(P<0 \cdot 05)$. In conclusion, all data suggested that astaxanthin was better than canthaxanthin as the dietary carotenoid source in the commercial diet of P. monodon, and the supplement of cholesterol could positively enhance the efficiency of astaxanthin and canthaxanthin.
\end{abstract}

Key words: Penaeus monodon: Astaxanthin: Canthaxanthin: Cholesterol

Carotenoids could yield beneficial effects on growth, survival or maturation in black tiger shrimp (Penaeus monodon) ${ }^{(1-3)}$, Pacific white shrimp (Litopenaeus vannamei) ${ }^{(4)}$ and kuruma prawn (Marsupenaeus japonicus) ${ }^{(5)}$. Moreover, dietary supplementation of carotenoids improved or corrected the colour of penaeids, especially those intensively cultured, for a better market price ${ }^{(4)}$. Besides pigmentation properties of carotenoids, increasing attention is being directed towards defining the biological function of astaxanthin in aquatic animals ${ }^{(4)}$. Among the biological functions of carotenoids in aquaculture, as summarised by Niu et al. ${ }^{(6)}$, the antioxidant properties can be closely associated with stress resistance. Recent studies have shown that enhancement of resistance to dissolved oxygen (DO) depletion stress ${ }^{(4)}$, salinity stress ${ }^{(1)}$, thermal stress ${ }^{(1)}, \mathrm{NH}_{3}$ stress $^{(7)}$ and pathological stress $^{(8)}$ in penaeids was associated with an increase in dietary and body carotenoids, especially astaxanthin.

Astaxanthin and canthaxanthin are the major carotenoid pigments used in aquatic feeds to achieve the natural colour desired by consumers ${ }^{(9)}$. Shrimp are unable to biosynthesise

Abbreviations: ADC, apparent digestibility coefficient; ALT, alanine aminotransferase; AST, aspartate aminotransferase; D1, control diet; D2, 0.1\% astaxanthin; D3, 0.2\% astaxanthin; D4, $0.1 \%$ astaxanthin $+1 \%$ cholesterol; D5, 0.07\% canthaxanthin; D6, 0.13\% canthaxanthin; D7, 0.07\% canthaxanthin $+1 \%$ cholesterol; DO, dissolved oxygen; FCR, feed conversion ratio; SGR, specific growth rate; SOD, superoxide dismutase; TAS, total antioxidant status; WG, weight gain.

*Corresponding author: H.-Z. Lin, fax +86 208445 1442, email linheizhao@163.com 
carotenoids de novo but can convert synthetic canthaxanthin in feed to deposit in the body as astaxanthin ${ }^{(9)}$. It has always been assumed that astaxanthin is preferable to canthaxanthin because it produces nature-identical pigmentation and is more efficiently deposited. Okada et al. ${ }^{(10)}$ indicated that astaxanthin is the predominant pigment (86-98\% of total carotenoids) in penaeids and other crustaceans. Species differences appear to exist in pigmentation retention efficiencies. Astaxanthin is about 1.4 times more efficient as a carotenoid source than canthaxanthin for muscle pigmentation of rainbow trout (Oncorbynchus mykiss) ${ }^{(11)}$; however, canthaxanthin is better than astaxanthin for muscle pigmentation of Atlantic salmon (Salmo salar) ${ }^{(12,13)}$. Obviously, the effectiveness of a carotenoid source in terms of deposition and pigmentation is species specific. To date, no study has been designed to compare the effect of dietary astaxanthin and canthaxanthin on the growth performance and pigmentation efficiency of $P$. monodon.

Pigmentation depends not only on the occurrence of the dietary carotenoid source, but also on other factors such as absorption and transport in the blood that limit the amount of astaxanthin retained in the muscle. The colour of the muscle is caused by the uptake, accumulation and metabolic transformation of ingested carotenoids. However, the efficiency of carotenoids for trout muscle pigmentation is very low, with only about $5-15 \%$ of the dietary carotenoids being utilised for muscle pigmentation ${ }^{(14,15)}$. The low degree of utilisation may be partly due to a low absorption rate in the gastrointestinal tract, deposition in other organs and metabolic transformation into colourless compounds that may eventually be excreted. Although retention of dietary carotenoids in muscle depends on intestinal absorption, transportation, metabolism and deposition of carotenoids in tissues $^{(16)}$, the biochemical mechanisms involved in these processes are not clear and have been subjected to limited investigation. A common measure of gastrointestinal absorption is the apparent digestibility coefficient (ADC); typical values for the ADC of astaxanthin and canthaxanthin for salmon fish are between 30 and $60 \%{ }^{(13)}$, but higher or lower values may be found depending on dietary dose and species difference. No such data about ADC of astaxanthin and canthaxanthin have been published in shrimp.

Carotenoids are lipid-soluble compounds. Therefore, the amount and type of fat present in the diet may influence carotenoid bioavailability ${ }^{(17)}$. Several studies involving different types of dietary lipid have produced conflicting results in salmon fish. Atlantic salmon (S. salar L.) fed diets containing high $n$-3 PUFA oil had higher muscle astaxanthin content than salmon fed diets containing herring oil ${ }^{(18)}$. However, no difference in astaxanthin concentration has been noted in the muscle of salmon when fish oil was replaced by rapeseed oil $^{(19)}$ or palm oil ${ }^{(20)}$. Recently, Salvador et al. ${ }^{(21)}$ assessed the effect of a progressive increase in dietary phospholipid levels in the transport of cholesterol and canthaxanthin by serum lipoproteins and their deposition in trout muscle. Results showed that the addition of dietary extra phospholipid is not necessary to increase cholesterol and canthaxanthin and thus fish pigmentation. It is a well-known fact that carotenoids are lipid-soluble compounds, which are divided into two subclasses: more polar compounds called xanthophylls or oxycarotenoids, and non-polar hydrocarbon carotenes ${ }^{(22)}$. Examples of xanthophylls include astaxanthin, canthaxanthin, capsanthin, lutein, zeaxanthin and $\beta$-cryptoxanthin. Hydrocarbon carotenoids include $\alpha$-carotene, $\beta$-carotene and $\gamma$-carotene ${ }^{(22)}$. Being lipid soluble, it is possible that more polar carotenoids, which are mainly located in the lipoprotein surface of the lipid droplets, are more easily transferred than the less polar carotenoids that are mainly located in the lipoprotein core of the droplets $^{(23)}$. This is probably a very important step because presumably the efficiency of this transfer directly affects the accessibility of carotenoids. van Het Hof et al. ${ }^{(24)}$ stated that the transfer is assumed to occur in two steps. First, carotenoids must be released from the dietary matrix. The second step is the transfer of carotenoids to lipid micelles in the intestines This requires the presence of dietary fat in the intestine, which stimulates the release of bile acids that are amphipathic compounds synthesised by liver and that allow the binding of both lipophilic and hydrophilic molecules ${ }^{(21)}$. Amphipathic properties of bile acids are important in the intestinal lumen for the formation of mixed micelles and liposomes during the emulsification and digestion of lipids and lipid-soluble compounds such as astaxanthin and canthaxanthin ${ }^{(25)}$. Released carotenoids must be assimilated into the mixed lipid micelles in the lumen of the intestine, most probably orienting themselves at the micelle surface. Polar compounds make up the exterior of the micelle, acting as a carrier for the carotenoids to travel through the hydrophilic chyme in the intestine to the intestinal mucosal cell surface ${ }^{(22)}$. In rats, the high basal level of cholesterol $7-\alpha$ hydroxylase was induced by dietary cholesterol, allowing these animals to convert excess dietary cholesterol to bile acids efficiently ${ }^{(26)}$. The inclusion of the bile acid, in the diet of ferrets ${ }^{(27)}$ and rats $^{(28)}$, significantly increased the absorption and tissue accumulation of carotenoids. However, information on the effect of dietary cholesterol on the utilisation of carotenoids has not been reported in shrimp.

The present study was designed to assess the effect of astaxanthin or canthaxanthin on the growth, survival, pigmentation and antioxidant capacity of $P$. monodon, and whether dietary cholesterol supplement could improve the efficacy of astaxanthin and canthaxanthin in terms of digestibility, retention efficiency and tissue contents of carotenoids (astaxanthin or canthaxanthin)

\section{Materials and methods}

\section{Diet preparation and dietary treatments}

The formulation and proximate composition of the seven experimental diets (D1: control diet; D2: 0.1\% astaxanthin; D3: $0 \cdot 2 \%$ astaxanthin; D4: $0 \cdot 1 \%$ astaxanthin $+1 \%$ cholesterol; D5: $0.07 \%$ canthaxanthin; D6: $0.13 \%$ canthaxanthin; D7: $0.07 \%$ canthaxanthin $+1 \%$ cholesterol) with different carotenoid sources (Carophyll Pink, 10\% astaxanthin and $15 \%$ canthaxanthin; DSM Nutritional Products France SAS Siant Louis Cedex, France) are presented in Tables 1 and 2 
Table 1. Composition of the basal diet

\begin{tabular}{ll}
\hline Ingredients & $\%$ \\
\hline Fish meal & $30 \cdot 09$ \\
Soyabean meal & 19 \\
Peanut bran & 16 \\
Wheat flour & 20 \\
Beer yeast & 5 \\
Phytosterol & $0 \cdot 3$ \\
Cholesterol & 0 \\
Cellulose & $1 \cdot 2$ \\
Soyabean lecithin & 1 \\
Fish oil & 1 \\
Soyabean oil & 1 \\
Choline chloride (50\%) & $0 \cdot 3$ \\
Monocalcium phosphate & 1 \\
Vitamin premix* & 1 \\
Mineral premix* & 1 \\
Ascorbic phosphate ester & $0 \cdot 1$ \\
Sodium alginate & 2 \\
Yi $_{2} \mathrm{O}_{3}$ & $0 \cdot 01$ \\
\hline${ }^{*}$ According to Bautista-Teruel et al. ${ }^{(62)}$. & \\
\end{tabular}

The method of diet preparation was the same as described by Niu et al. ${ }^{(4)}$. Briefly, all the dry ingredients of the experimental diets were weighed, combined and thoroughly mixed to homogeneity in a Hobart-type mixer. Oil was then added and thoroughly mixed for $5 \mathrm{~min}$. Deionised water ( $40 \%$ dry ingredient mixture) was added and mixed for another $5 \mathrm{~min}$. The wet mixture was placed in a monoscrew extruder (Institute of Chemical Engineering, South China University of Technology, Guangzhou, China) and extruded through a $1.2 \mathrm{~mm}$ die. $\mathrm{Y}_{2} \mathrm{O}_{3}$ was used as an inert marker at a concentration of $0.01 \%$ in the diets. The resulting pellets were dried at $25^{\circ} \mathrm{C}$ with the aid of an air conditioner and an electrical fan. All the diets were stored at $-20^{\circ} \mathrm{C}$ until used.

\section{Shrimp and experimental condition}

Juvenile $P$. monodon were obtained from a semi-intensive culture pond near Hongsha Bay, Sanya, Hainan Province. Shrimp were acclimatised to the experimental conditions and fed the control diet for 2 weeks to equalise their body carotenoid content before the start of the experiment. Experimental procedures complied with the institutional recommendations for the care and use of animals for scientific purposes of the
Ministry of Agriculture, China, and all protocols were approved by the local ethics board of South China Sea Fisheries Research Institute, Chinese Academy of Fishery Sciences. There were no aspects of the present trial that would cause aggravated or unnecessary harm or stress to the shrimp. A total of 630 healthy shrimp with an initial body weight of 1.19 (SE 0.01$) \mathrm{g}$ were randomly distributed into twenty-one fibreglass aquaria (500 litres, three aquaria per diet, thirty shrimp per aquarium). Water exchange in each aquarium was adjusted to approximately 1.0 litre $/ \mathrm{min}$ with a flowing filtered water system. Each aquarium was covered by a plastic mesh lid to prevent the shrimp from jumping out. The shrimp were cultured outdoors with a steel awning and subjected to a natural photoperiod. During the experimental period, water temperature, salinity, $\mathrm{DO}$ and total $\mathrm{NH}_{3} \mathrm{~N}$ ranged from $24 \cdot 0$ to $26 \cdot 5^{\circ} \mathrm{C}, 29 \cdot 0$ to $30 \cdot 0 \mathrm{~g} / \mathrm{l}, 6.5$ to $7.0 \mathrm{mg} / 1$ and 0.3 to $0.5 \mathrm{mg} / 1$, respectively.

All shrimp in each aquarium were initially fed $6 \%$ of their total body weight daily in accordance with Shiau et al. ${ }^{(29)}$. The feeding frequency was three times per $\mathrm{d}$ at 07.00, 13.00 and 21.00 hours and lasted for $74 \mathrm{~d}$. During the feeding trial, the amount of the diet given was progressively changed and adjusted according to the appetite of shrimp by checking the bottom of the aquaria for excess feed remaining $2 \mathrm{~h}$ after feeding. In this way, overfeeding was minimised and shrimp were fed close to satiation. Every morning and afternoon before each feeding time, all residual/uneaten feed, faeces, moults and dead shrimp were siphoned from the aquaria. Every 2 weeks, shrimp from each aquarium were weighed and counted to evaluate growth and survival. In the final $14 \mathrm{~d}$, faecal matter was siphoned from each aquarium two times per $\mathrm{d}$ at 08.00 and 14.00 hours within $30 \mathrm{~min}$ after egestion. If present, uneaten feed particles, which were dyed red, were easily sorted from the faeces strands and discarded. Faeces were then rinsed with double-distilled water to avoid contamination by salt and frozen at $-20^{\circ} \mathrm{C}$. The samples were freeze-dried until analysis ${ }^{(30)}$.

\section{Sample collection and chemical analysis}

Before rearing, enough shrimp were collected randomly for the analysis of whole-body, muscle and shell carotenoids.

Table 2. Formulation and proximate composition of each diet (\% DM)

(Mean values with their standard errors of three replicates)

\begin{tabular}{|c|c|c|c|c|c|c|c|c|c|c|c|c|c|c|}
\hline & Mean & SE & Mean & SE & Mean & SE & Mean & SE & Mean & SE & Mean & SE & Mean & SE \\
\hline Basal diet & \multicolumn{2}{|c|}{100} & \multicolumn{2}{|c|}{99.9} & \multicolumn{2}{|c|}{$99 \cdot 8$} & \multicolumn{2}{|c|}{$98 \cdot 9$} & \multicolumn{2}{|c|}{99.93} & \multicolumn{2}{|c|}{99.87} & \multicolumn{2}{|c|}{98.93} \\
\hline Astaxanthin (10\%) & \multicolumn{2}{|c|}{0} & \multicolumn{2}{|c|}{0.1} & \multicolumn{2}{|c|}{0.2} & \multicolumn{2}{|c|}{0.1} & \multicolumn{2}{|c|}{0} & \multicolumn{2}{|c|}{0} & \multicolumn{2}{|c|}{0} \\
\hline Canthaxanthin (15\%) & \multicolumn{2}{|c|}{0} & \multicolumn{2}{|c|}{0} & \multicolumn{2}{|c|}{0} & \multicolumn{2}{|c|}{0} & \multicolumn{2}{|c|}{0.07} & \multicolumn{2}{|c|}{0.13} & \multicolumn{2}{|c|}{0.07} \\
\hline Cholesterol & \multicolumn{2}{|c|}{0} & \multicolumn{2}{|c|}{0} & \multicolumn{2}{|c|}{0} & \multicolumn{2}{|c|}{1} & \multicolumn{2}{|c|}{0} & \multicolumn{2}{|c|}{0} & \multicolumn{2}{|c|}{1} \\
\hline \multicolumn{15}{|l|}{ Proximate composition } \\
\hline Moisture & $9 \cdot 03$ & 0.06 & 8.89 & 0.14 & 8.99 & 0.07 & 8.93 & 0.12 & $8 \cdot 96$ & 0.05 & 8.99 & 0.04 & $9 \cdot 00$ & 0.01 \\
\hline Crude protein & $45 \cdot 6$ & 0.22 & $45 \cdot 5$ & 0.13 & $45 \cdot 3$ & 0.05 & 45.5 & 0.06 & $45 \cdot 6$ & 0.25 & $45 \cdot 3$ & 0.18 & 45.5 & 0.13 \\
\hline Crude lipid & $7 \cdot 59^{a}$ & 0.02 & $7 \cdot 55^{a}$ & 0.20 & $7 \cdot 53^{a}$ & 0.19 & $8.55^{b}$ & 0.01 & $7 \cdot 60^{a}$ & 0.19 & $7 \cdot 57^{a}$ & 0.02 & $8 \cdot 44^{b}$ & 0.07 \\
\hline Ash & $9 \cdot 12$ & 0.01 & $9 \cdot 11$ & 0.08 & $9 \cdot 11$ & 0.01 & $9 \cdot 13$ & 0.05 & $9 \cdot 10$ & 0.04 & $9 \cdot 11$ & 0.02 & $9 \cdot 11$ & 0.01 \\
\hline Astaxanthin $(\mathrm{mg} / \mathrm{g})$ & \multicolumn{2}{|c|}{$0.59 \times 10^{-4}$} & \multicolumn{2}{|c|}{0.11} & \multicolumn{2}{|c|}{0.23} & \multicolumn{2}{|c|}{0.11} & \multicolumn{2}{|c|}{$0.57 \times 10^{-4}$} & \multicolumn{2}{|c|}{$0.55 \times 10^{-4}$} & $0.59 \times$ & $10^{-4}$ \\
\hline Canthaxanthin (mg/g) & $0.90 \times$ & $10^{-4}$ & $0.86 \times$ & $10^{-4}$ & $0.88 \times$ & $10^{-4}$ & $0.92 \times$ & $10^{-4}$ & 0.1 & & 0 . & & 0 & \\
\hline Carotenoids $(\mathrm{mg} / \mathrm{g})$ & $0.15 \times$ & $10^{-3}$ & 0.1 & & 0. & & 0. & & 0.1 & & 0 . & & 0 & \\
\hline
\end{tabular}

${ }^{\mathrm{a}, \mathrm{b}}$ Mean values within the same row with unlike superscript letters were significantly different $(P<0.05)$. 
At the end of the feeding trial, six shrimp from each aquarium were randomly collected for whole-body, muscle, skin and haemolymph samples. The time elapsed between the last meal and blood sampling was within $2 \mathrm{~h}$ (see Barbosa et $a{ }^{(11)}$ ). Haemolymph was drawn by inserting a needle into the pericardial cavity through the intersegmental membrane between the cephalothorax and the abdominal segment. Haemolymph samples were prepared by mixing $400 \mu \mathrm{l}$ isotonic $\mathrm{NaCl}$ solution containing 0.94 M-EDTA with $100 \mu \mathrm{l}$ haemolymph immediately after withdrawing the haemolymph. Then, plasma was separated by centrifugation (12000 rpm, Eppendorf 5810R; Eppendorf, Hamburg, Germany) and the concentration of carotenoids was measured immediately. Skin, haemolymph and muscle samples were dissected and frozen immediately in liquid $\mathrm{N}_{2}$ and stored at $-70^{\circ} \mathrm{C}$ for later analysis.

Samples from the diets and faecal material were freeze-dried (Advantage 2.0; VirTis, Pasadena, CA, USA) and then ground. Moisture, crude protein, crude lipid and crude ash of the diets and faecal were determined using standard methods ${ }^{(31)}$. Moisture was determined by oven drying at $105^{\circ} \mathrm{C}$ for $24 \mathrm{~h}$, and ash was determined using a muffle furnace at $550^{\circ} \mathrm{C}$ for $24 \mathrm{~h}$. Crude protein was analysed by the Kjeldahl method after acid digestion (1030-Auto-analyzer; Tecator, Hoganos, Sweden). Crude lipid was determined by the diethyl ether extraction method using a Soxtec System HT (Soxtec System HT6; Tecator). Energy of the diets and faecal material were determined by an adiabatic micro-bomb calorimeter (HR-15A adiabatic calorimeter; Human Changxing Higher Education Equipment Development Co., Ltd, Changsha, China). Yttrium was analysed using inductively coupled plasma MS (model: IRIS Advantage (HR); Thermo Jarrel Ash Corporation, Boston, MA, USA), as described by Refstie et al. ${ }^{(32)}$.

To measure haemolymph TAS and superoxide dismutase (SOD), 20 and $25 \mu$ l of the haemolymph sample were used and determined spectrophotometrically at 600 and $505 \mathrm{~nm}$, respectively, with a U-2000 spectrophotometer (Hitachi, Tokyo, Japan) at $37^{\circ} \mathrm{C}$ using ELISA kits (Randox Laboratories Limited, Crumlin, UK), according to the manufacturer's instructions. Total soluble protein $(\mathrm{mg} / \mathrm{ml})$ was measured with the Bradford method using bovine serum albumin as a standard. The TAS activity was expressed as $\mathrm{mol} / \mathrm{ml}$ haemolymph and SOD activity was expressed as $\mathrm{U} / \mathrm{mg}$ protein.

For aspartate aminotransferase (AST) and alanine aminotransferase (ALT) activities, $100 \mu \mathrm{l}$ of the haemolymph sample were used and determined spectrophotometrically at $340 \mathrm{~nm}$ with a U-2000 spectrophotometer (Hitachi) at $37^{\circ} \mathrm{C}$ using ELISA kits (Randox Laboratories Limited), according to the manufacturer's instructions. Activities were expressed as $\mathrm{U} / \mathrm{mg}$ protein.

The analysis of carotenoids was carried out in triplicate, and the general precautions recommended for the isolation and handling of the carotenoids, as referred to by Barbosa et $a{ }^{(11)}$, were followed. The extraction of diet and faecal carotenoids was performed according to the method of Schierle \& Hardi ${ }^{(33)}$. The extraction of carotenoids from skin samples was carried out according to the method of Schiedt et $a{ }^{\left({ }^{(34)}\right.}$. The extraction of carotenoids from muscle samples was performed according to the method of Boonyaratpalin et al. ${ }^{(9)}$. Plasma carotenoids were extracted using a portable sonic probe according to the method of Kiessling et al. ${ }^{(13)}$.

\section{HPLC conditions}

Astaxanthin and canthaxanthin were analysed by HPLC, using a Hitachi L-6200 pump, a silica column (Lichrosorb Si-60 5 micro $250 \times 4.6 \mathrm{~mm}$ column inner diameter; E. Merck, Darmstadt, Germany), a Hitachi L-4250 UV-VIS detector at $470 \mathrm{~nm}$ and a Hitachi D-2000 Chromato-Integrator. The operational conditions were as follows: mobile phase, $14 \%$ acetone in $n$-hexane; solvent flow rate, $1.5 \mathrm{ml} / \mathrm{min}$; injection volume, $100 \mu \mathrm{l}$; pump programme, the sequence was 0-20 min mixture $\mathrm{A}$ and 20.5-40 min mixture $\mathrm{B}$; mixture A was acetone- $n$-hexane (14:86) and mixture B was $100 \%$ $n$-heptane. This system was controlled by a chromatographic data system (Scientific Information Services, Davis, CA, USA), which also integrated the areas under the peaks. The astaxanthin and canthaxanthin standards were chromatographically pure astaxanthin and canthaxanthin and purchased from Sigma (St Louis, MO, USA). Sample concentrations were integrated against external standards of known concentrations measured using a V530 UV/Vis spectrophotometer (Jasco (UK) Limited, Great Dunmow, Essex, UK), with an extinction coefficient of $E_{1 \%, 1 \mathrm{~cm}}=2100$ at an absorbance maximum $\left(\lambda_{\max }=470 \mathrm{~nm}\right)$ for astaxanthin $^{(29)}$, and $E_{1 \%, 1 \mathrm{~cm}}=2260$ at an absorbance maximum of $\left(\lambda_{\max }=466 \mathrm{~nm}\right)$ for canthaxanthin ${ }^{(35)}$.

Tissue carotenoids, astaxanthin and canthaxanthin are expressed on a dry weight basis to eliminate potential error resulting from variations in shrimp moisture content associated with different stages of the moult cycle ${ }^{(36)}$.

\section{Low dissolved oxygen stress tolerance test}

The method of low DO stress tolerance test was the same as described by Niu et al. ${ }^{(4)}$. At the end of the experiment, thirty shrimp from each dietary treatment were selected randomly and transferred to triplicate of stress test chambers consisting of 50 litre white plastic barrels with ten shrimp per chamber. Low DO conditions were maintained by stopping the aeration and the water flow through the system, and using a plastic sheet overlying on the water surface in each stress test chamber. DO linearly decreased to $0.8-1 \mathrm{mg} / 1$ within $10 \mathrm{~h}$. DO in the test chamber was measured using an oxygen meter. The stress condition was carried out only during the daytime for $10 \mathrm{~h}$ (08.00-18.00 hours) per $\mathrm{d}$, and then returned to a normal condition in the evening. Shrimp were stressed in this way for seven consecutive days. Survival in each group was recorded daily.

\section{Calculations and statistical analysis}

Biological parameters used to evaluate the quality of diets were calculated by the following equations: 
Weight gain $(W G)(\%)=100 \times($ final mean weight - initial mean weight)/initial mean weight,

Specific growth rate $(\mathrm{SGR})(\% / \mathrm{d})=100 \times(\ln$ final weight ln initial weight)/total number of experimental days,

Survival $(\%)=100 \times$ number of final shrimp/number of initial shrimp,

Feed conversion ratio $(\mathrm{FCR})=$ dry feed intake/wet WG,

Carotenoid retention efficiency in whole body $(\%)=100 \times$ (carotenoid content of final whole body - carotenoid content of initial whole body)/carotenoid intake,

Carotenoid retention efficiency in muscle $(\%)=100 \times$ (carotenoid content of final muscle - carotenoid content of initial muscle)/carotenoid intake,

Carotenoid retention efficiency in shell $(\%)=100 \times$ (carotenoid content of final shell - carotenoid content of initial shell)/carotenoid intake,

$$
\operatorname{ADC}(\%)=100 \times\left(1-\left(y_{\mathrm{i}} / y_{\mathrm{f}}\right) \times\left(n_{\mathrm{f}} / n_{\mathrm{i}}\right)\right),
$$

where $y_{\mathrm{i}}$ is the yttrium trioxide content in the feed; $y_{\mathrm{f}}$ is the yttrium trioxide content in the faeces; $n_{\mathrm{i}}$ is the nutrient content in the feed; $n_{\mathrm{f}}$ is the nutrient content in the faeces.

All the data from triplicate tanks of each diet were analysed using one-way ANOVA and Duncan's multiple-range test. All statistical analyses were performed using the software SPSS (version 16.0; SPSS, Inc., Chicago, IL, USA). Differences were considered significant at $P<0 \cdot 05$.

\section{Results}

\section{Biological performance of shrimp}

The biological performance of shrimp is shown in Table 3 . The results showed that survival was in the range of 55.56$81 \cdot 11 \%$. The survival of shrimp in the D4 treatment was higher than that of shrimp in the D1 and D5-D7 treatments $(P<0.05)$, while no differences were found among the three astaxanthin-supplemented dietary treatments (D2-D4; $P>0.05)$. The maximum WG was observed in shrimp fed D4, which was different from that of shrimp fed all the other diets $(P<0 \cdot 05)$. The second maximum WG was observed in shrimp fed D7, which was not different from that of shrimp fed D2 and D3 $(P>0.05)$ but different from that of shrimp fed D1, D5 and D6 $(P<0.05)$. The highest and lowest SGR were observed in shrimp fed D4 and D1, respectively. SGR of shrimp fed D2, D3 and D5-D7 were intermediate and no significant differences were found among the D2, D3 and D5-D7 treatments. The best FCR was observed in shrimp fed D4, whereas the poorest FCR was observed in shrimp fed D1.

\section{Tissue carotenoid retention efficiency}

Carotenoid retention efficiencies in tissues (whole body, muscle and shell) are shown in Table 4. The maximum carotenoid retention efficiencies in tissues were all observed in shrimp fed D4, which were different from those of shrimp fed the other diets $(P<0.05)$, followed by shrimp fed D7. Among the three astaxanthin-supplemented dietary treatments

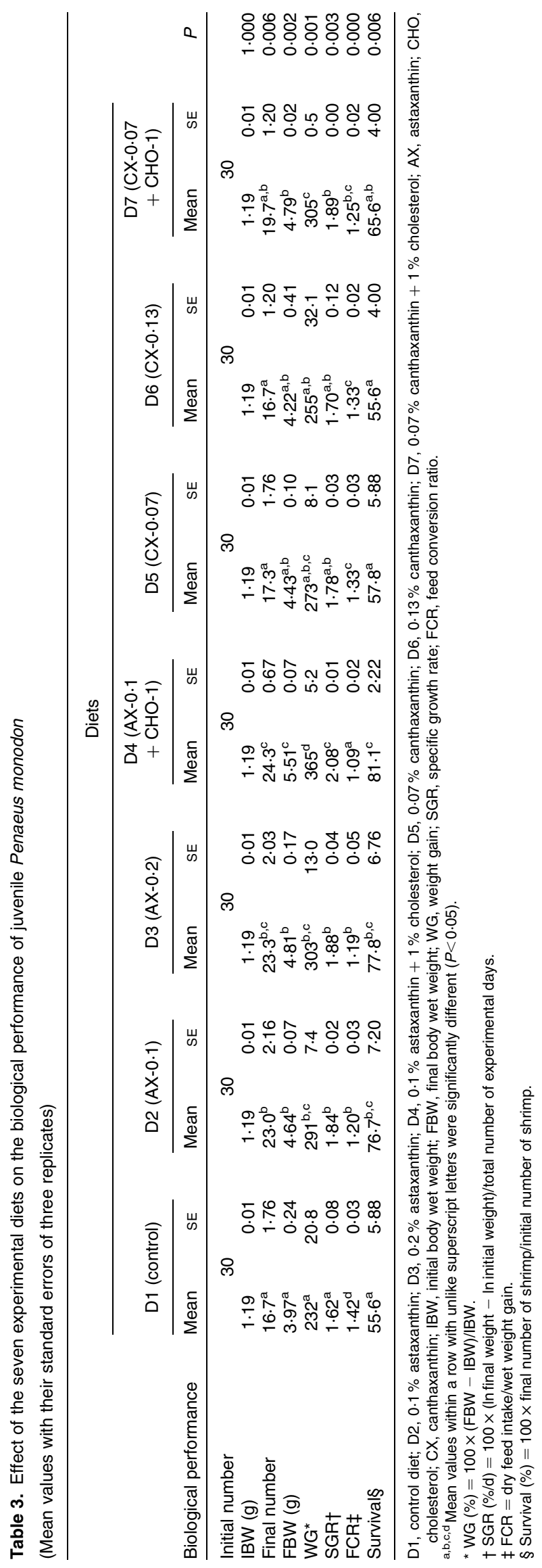


Table 4. Carotenoid retention efficiency (\%) in the whole body, muscle and shell of shrimp fed the seven experimental diets (Mean values with their standard errors of three replicates)

\begin{tabular}{|c|c|c|c|c|c|c|c|c|c|c|c|c|c|}
\hline \multirow{3}{*}{$\begin{array}{l}\text { Carotenoid retention } \\
\text { efficiency }\end{array}$} & \multicolumn{12}{|c|}{ Diets } & \multirow[b]{3}{*}{$P$} \\
\hline & \multicolumn{2}{|c|}{$\mathrm{D} 2(\mathrm{AX}-0 \cdot 1)$} & \multicolumn{2}{|c|}{ D3 (AX-0.2) } & \multicolumn{2}{|c|}{$\begin{array}{l}\mathrm{D} 4(\mathrm{AX}-0 \cdot 1 \\
+\mathrm{CHO}-1)\end{array}$} & \multicolumn{2}{|c|}{ D5 (CX-0.07) } & \multicolumn{2}{|c|}{ D6 (CX-0.13) } & \multicolumn{2}{|c|}{$\begin{array}{l}\text { D7 (CX-0.07 } \\
+ \text { CHO-1) }\end{array}$} & \\
\hline & Mean & SE & Mean & SE & Mean & SE & Mean & SE & Mean & SE & Mean & SE & \\
\hline Whole body* & $16 \cdot 4^{c}$ & 0.32 & $16 \cdot 6^{c}$ & 0.40 & $43 \cdot 2^{\mathrm{e}}$ & 0.83 & $14 \cdot 2^{\mathrm{b}}$ & 0.19 & $9 \cdot 40^{\mathrm{a}}$ & 0.27 & $21 \cdot 5^{d}$ & 0.50 & 0.000 \\
\hline Muscle† & $26 \cdot 9^{c}$ & 0.39 & $15 \cdot 5^{\mathrm{a}}$ & 0.37 & $43 \cdot 2^{\mathrm{e}}$ & 0.21 & $22 \cdot 9^{b}$ & 0.39 & $15 \cdot 0^{\mathrm{a}}$ & 0.32 & $32 \cdot 0^{d}$ & 0.36 & 0.000 \\
\hline Shell & $19 \cdot 5^{c}$ & 0.35 & $14 \cdot 3^{b}$ & 0.14 & $24 \cdot 9^{\mathrm{e}}$ & 0.17 & $12 \cdot 9^{a}$ & 0.17 & $12 \cdot 4^{\mathrm{a}}$ & 0.12 & $24 \cdot 2^{\mathrm{d}}$ & 0.18 & 0.000 \\
\hline
\end{tabular}

D2, $0.1 \%$ astaxanthin; D3, $0.2 \%$ astaxanthin; D4, $0.1 \%$ astaxanthin $+1 \%$ cholesterol; D5, $0.07 \%$ canthaxanthin; D6, $0.13 \%$ canthaxanthin; D7, $0.07 \%$ canthaxanthin $+1 \%$ cholesterol; $\mathrm{AX}$, astaxanthin; $\mathrm{CHO}$, cholesterol; $\mathrm{CX}$, canthaxanthin.

a,b,c,d,e Mean values within a row with unlike superscript letters were significantly different $(P<0.05)$.

${ }^{*}$ Carotenoid retention efficiency in whole body $(\%)=100 \times($ carotenoid content of final whole body - carotenoid content of initial whole body)/carotenoid intake.

† Carotenoid retention efficiency in muscle $(\%)=100 \times$ (carotenoid content of final muscle - carotenoid content of initial muscle)/carotenoid intake.

$\ddagger$ Carotenoid retention efficiency in shell $(\%)=100 \times($ carotenoid content of final shell - carotenoid content of initial shell $) /$ carotenoid intake.

(D2-D4), the sequence of carotenoid retention efficiencies in tissues (whole body, muscle and shell) from high to low was D4, then D2 and D3. Among the three canthaxanthinsupplemented dietary treatments (D5-D7), the sequence of carotenoid retention efficiencies in tissues (whole body, muscle and shell) from high to low was D7, then D5 and D6.

\section{Body colour and the carotenoid, astaxanthin and} canthaxanthin contents of whole body, muscle, skin and plasma

The body colour difference of shrimp among the diet treatments was first observed on week 2 . The shrimp fed the astaxanthin- or canthaxanthin-supplemented diets exhibited more dark-brown colour when compared with the control group (Fig. 1). At the end of the feeding trial, the red colour of the boiled shrimp in the D4 treatment was higher than the others, and the light-yellow colour was observed in the control group (Fig. 2).

The total carotenoid, astaxanthin and canthaxanthin contents of whole body, muscle, skin and plasma are shown in Table 5. The shrimp fed the astaxanthin-supplemented diets (D2-D4) showed higher $(P<0.05)$ whole-body and muscle carotenoid concentrations (astaxanthin and canthaxanthin)

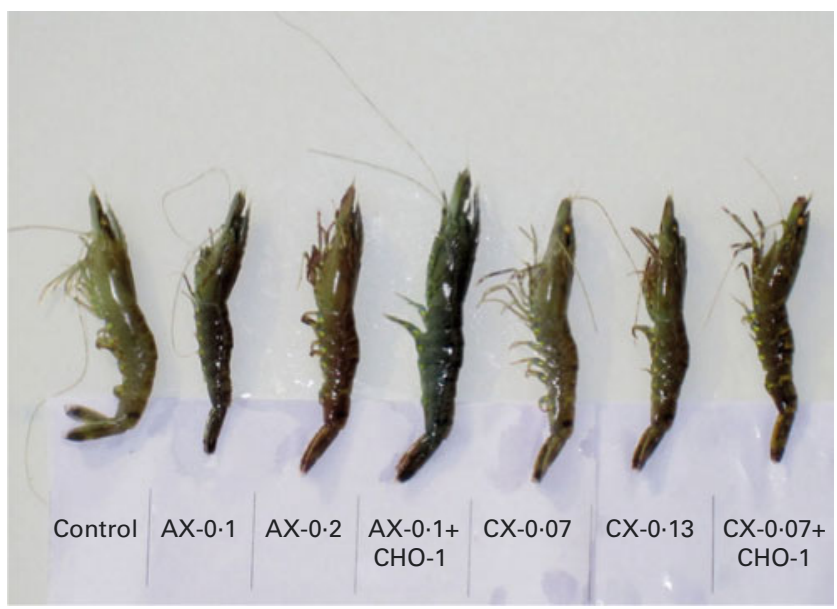

Fig. 1. Colour of live Penaeus monodon fed on the seven experimental diets. $\mathrm{AX}$, astaxanthin; $\mathrm{CX}$, canthaxanthin; $\mathrm{CHO}$, cholesterol. than those fed the control and canthaxanthin-supplemented diets (D1 and D5-D7). Moreover, the shrimp fed the diets containing additional cholesterol displayed higher $(P<0.05)$ whole-body and muscle carotenoid (astaxanthin and canthaxanthin) levels than those fed the diets without additional cholesterol. The shrimp fed D4 showed the highest levels of whole-body and muscle carotenoids (astaxanthin and canthaxanthin), while the shrimp fed D1 presented the lowest levels of whole-body and muscle carotenoids (astaxanthin and canthaxanthin).

Astaxanthin concentrations of shell and plasma were higher $(P<0.05)$ for the shrimp fed the astaxanthinsupplemented diets (D2-D4) than for those fed the control and canthaxanthin-supplemented diets (D1 and D5-D7). While canthaxanthin concentrations of shell and plasma were lower $(P<0.05)$ for the shrimp fed the control and astaxanthin-supplemented diets (D1-D4) than for those fed the canthaxanthin-supplemented diets (D5-D7).

\section{Apparent digestibility coefficient of dietary components and energy}

ADC of protein, DM, carotenoids (astaxanthin or canthaxanthin) and energy of the experimental diets for juvenile $P$. monodon are shown in Table 6. No differences were found in the ADC of protein, DM and energy among all the experimental diets for juvenile $P$. monodon $(P>0.05)$. The ADC of astaxanthin in the D2-D4 treatments were higher than those

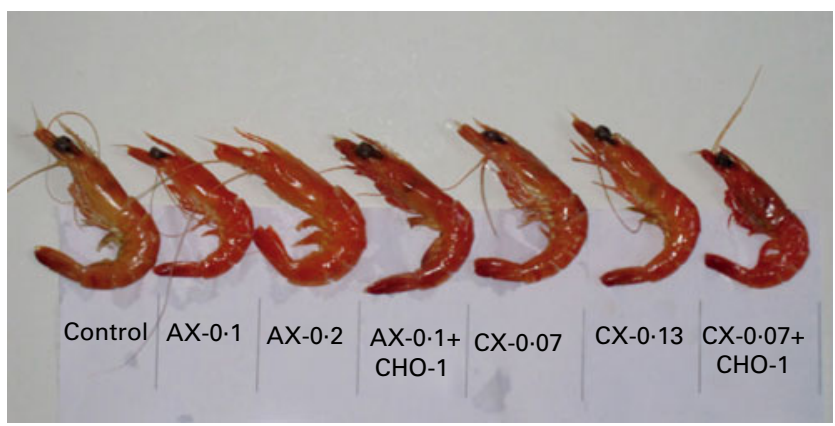

Fig. 2. Colour of boiled Penaeus monodon fed on the seven experimental diets. $\mathrm{AX}$, astaxanthin; $\mathrm{CX}$, canthaxanthin; $\mathrm{CHO}$, cholesterol. 
Table 5. Contents of carotenoids, astaxanthin (AX) and canthaxanthin (CX), of whole body (mg/g), muscle ( $\mathrm{mg} / \mathrm{g})$, shell ( $\mathrm{mg} / \mathrm{g})$ and plasma ( $\mu \mathrm{g} / \mathrm{ml})$ from the shrimp fed the seven experimental diets (Mean values with their standard errors of three replicates)

\begin{tabular}{|c|c|c|c|c|c|c|c|c|c|c|c|c|c|c|c|}
\hline \multirow[b]{3}{*}{ Carotenoid contents } & \multicolumn{14}{|c|}{ Diets } & \multirow[b]{3}{*}{$P$} \\
\hline & \multicolumn{2}{|c|}{ D1 (control) } & \multicolumn{2}{|c|}{ D2 (AX-0.1) } & \multicolumn{2}{|c|}{ D3 (AX-0.2) } & \multicolumn{2}{|c|}{$\begin{array}{r}\mathrm{D} 4(\mathrm{AX}-0 \cdot 1 \\
+\mathrm{CHO}-1)\end{array}$} & \multicolumn{2}{|c|}{ D5 (CX-0.07) } & \multicolumn{2}{|c|}{ D6 (CX-0.13) } & \multicolumn{2}{|c|}{$\begin{array}{c}\text { D7 (CX-0.07 } \\
+ \text { CHO-1) }\end{array}$} & \\
\hline & Mean & SE & Mean & SE & Mean & SE & Mean & SE & Mean & SE & Mean & SE & Mean & SE & \\
\hline \multicolumn{16}{|l|}{ Whole body (mg/g) } \\
\hline Carotenoids $\left(\times 10^{-4}\right)$ & $59 \cdot 16^{a}$ & 0.75 & $121 \cdot 7^{\mathrm{d}}$ & $6 \cdot 2$ & $168^{\mathrm{e}}$ & 4.9 & $230^{f}$ & 4.3 & $65 \cdot 5^{\mathrm{a}}$ & 0.58 & $79 \cdot 4^{b}$ & $1 \cdot 10$ & $96 \cdot 5^{\mathrm{c}}$ & 2.59 & 0.000 \\
\hline $\operatorname{AX}\left(\times 10^{-4}\right)$ & $50 \cdot 6^{\mathrm{a}}$ & 0.65 & $104^{\mathrm{d}}$ & $5 \cdot 70$ & $126^{\mathrm{e}}$ & $5 \cdot 20$ & $157^{f}$ & $1 \cdot 10$ & $54.9^{\mathrm{a}}$ & 1.80 & $77 \cdot 6^{\mathrm{b}}$ & $2 \cdot 15$ & $91 \cdot 2^{\mathrm{c}}$ & 1.50 & 0.000 \\
\hline $\mathrm{CX}\left(\times 10^{-4}\right)$ & $0.310^{\mathrm{a}}$ & 0.01 & $1 \cdot 38^{b, c}$ & 0.00 & $1.55^{\mathrm{c}}$ & 0.03 & $1.85^{\mathrm{e}}$ & 0.06 & $1 \cdot 21^{\mathrm{b}}$ & 0.01 & $1 \cdot 17^{b}$ & 0.07 & $1.71^{\mathrm{d}}$ & 0.02 & 0.000 \\
\hline Others $\left(\times 10^{-4}\right)$ & $8 \cdot 29^{a, b}$ & 1.39 & $17 \cdot 6^{\mathrm{b}}$ & $8 \cdot 35$ & $40 \cdot 27^{\mathrm{c}}$ & 5.98 & $72 \cdot 0^{\mathrm{e}}$ & 4.86 & $9 \cdot 38^{a, b}$ & 2.05 & $1 \cdot 28^{\mathrm{a}}$ & 0.75 & $3.42^{\mathrm{a}}$ & $2 \cdot 14$ & 0.000 \\
\hline \multicolumn{16}{|l|}{ Muscle $(\mathrm{mg} / \mathrm{g})$} \\
\hline Carotenoids $\left(\times 10^{-4}\right)$ & $22 \cdot 0^{\mathrm{a}}$ & $0 \cdot 16$ & $31 \cdot 1^{\mathrm{d}}$ & 0.28 & $31.4^{\mathrm{d}}$ & 0.42 & $38 \cdot 7^{\mathrm{e}}$ & 0.43 & $25 \cdot 9^{\mathrm{b}}$ & 0.54 & $27 \cdot 2^{\mathrm{c}}$ & 0.29 & $30 \cdot 4^{d}$ & 0.46 & 0.000 \\
\hline $\mathrm{AX}\left(\times 10^{-4}\right)$ & $11 \cdot 7^{\mathrm{a}}$ & 0.02 & $13 \cdot 1^{\mathrm{b}}$ & 0.39 & $13 \cdot 1^{\mathrm{b}}$ & 0.40 & $15 \cdot 2^{\mathrm{c}}$ & 0.55 & $11 \cdot 8^{\mathrm{a}, \mathrm{b}}$ & 0.15 & $12 \cdot 7^{\mathrm{a}, \mathrm{b}}$ & 0.66 & $13 \cdot 0^{\mathrm{b}}$ & 0.35 & 0.001 \\
\hline $\mathrm{CX}\left(\times 10^{-4}\right)$ & $4.95^{\mathrm{a}}$ & 0.05 & $8.03^{d}$ & 0.24 & $8.03^{\mathrm{d}}$ & 0.19 & $9 \cdot 17^{\mathrm{e}}$ & 0.03 & $5 \cdot 36^{b}$ & 0.09 & $5 \cdot 45^{\mathrm{b}}$ & 0.05 & $6 \cdot 40^{\mathrm{c}}$ & 0.04 & 0.000 \\
\hline Others $\left(\times 10^{-4}\right)$ & $5 \cdot 42^{\mathrm{a}}$ & $0 \cdot 14$ & $9 \cdot 94^{b, c}$ & 0.15 & $9 \cdot 99^{\mathrm{b}, \mathrm{c}}$ & 0.65 & $14 \cdot 3^{\mathrm{d}}$ & 0.88 & $8 \cdot 77^{b}$ & 0.46 & $9 \cdot 01^{b, c}$ & 0.81 & $10 \cdot 9^{c}$ & 0.79 & 0.000 \\
\hline \multicolumn{16}{|l|}{ Shell $(\mathrm{mg} / \mathrm{g})$} \\
\hline Carotenoids $\left(\times 10^{-4}\right)$ & $103^{\mathrm{a}}$ & 0.1 & $115^{\mathrm{c}}$ & 0.1 & $126^{\mathrm{d}}$ & 0.2 & $133^{\mathrm{e}}$ & 0.8 & $105^{\mathrm{a}, \mathrm{b}}$ & 0.1 & $109^{b}$ & 3.5 & $114^{\mathrm{c}}$ & 0.2 & 0.000 \\
\hline $\operatorname{AX}\left(\times 10^{-4}\right)$ & $16 \cdot 9^{\mathrm{a}}$ & 0.21 & $19 \cdot 5^{\mathrm{c}}$ & 0.19 & $23 \cdot 2^{d}$ & 0.21 & $25 \cdot 2^{\mathrm{e}}$ & 0.39 & $18 \cdot 4^{\mathrm{b}}$ & 0.32 & $18 \cdot 5^{\mathrm{b}}$ & 0.28 & $19.5^{\mathrm{C}}$ & 0.19 & 0.000 \\
\hline $\mathrm{CX}\left(\times 10^{-4}\right)$ & $0.05^{\mathrm{a}}$ & 0.00 & $0.06^{\mathrm{b}}$ & 0.00 & $0.09^{c}$ & 0.00 & $0.09^{c}$ & 0.00 & $0.21^{d}$ & 0.00 & $0.27^{e}$ & 0.00 & 0.36 & 0.00 & 0.000 \\
\hline Others $\left(\times 10^{-4}\right)$ & $86 \cdot 4^{\mathrm{a}}$ & 0.15 & $95 \cdot 2^{\mathrm{b}}$ & 0.22 & $103^{\mathrm{c}}$ & 0.40 & $108^{d}$ & 0.40 & $86 \cdot 0^{\mathrm{a}}$ & 0.36 & $88 \cdot 8^{\mathrm{a}}$ & 3.29 & $95 \cdot 2^{\mathrm{b}}$ & 0.26 & 0.000 \\
\hline \multicolumn{16}{|l|}{ Plasma $(\mu \mathrm{g} / \mathrm{ml})$} \\
\hline Carotenoids & $0.710^{\mathrm{a}}$ & 0.01 & $1.35^{\mathrm{c}}$ & 0.01 & $1.33^{\mathrm{c}}$ & 0.04 & $1.46^{\mathrm{d}}$ & 0.01 & $0.990^{\mathrm{b}}$ & 0.05 & $1.07^{b}$ & 0.03 & $1 \cdot 30^{\mathrm{c}}$ & 0.02 & 0.000 \\
\hline$A X$ & $0.490^{\mathrm{a}}$ & 0.05 & $0.810^{\mathrm{c}}$ & 0.02 & $0.940^{d}$ & 0.01 & $1.04^{\mathrm{e}}$ & 0.02 & $0.600^{\mathrm{b}}$ & 0.03 & $0.620^{\mathrm{b}}$ & 0.01 & $0.750^{c}$ & 0.06 & 0.000 \\
\hline$c x$ & $0.230^{\mathrm{a}}$ & 0.07 & $0.390^{\mathrm{b}}$ & 0.03 & $0.400^{b}$ & 0.04 & $0.410^{b}$ & 0.02 & $0.490^{\mathrm{b}}$ & 0.04 & $0.450^{\mathrm{b}}$ & 0.03 & $0.600^{c}$ & 0.05 & 0.002 \\
\hline
\end{tabular}

D1, control diet; D2, 0.1\% AX; D3, 0.2\% AX; D4, 0.1\% AX + 1\% cholesterol; D5, 0.07\% CX; D6, 0.13\% CX; D7, 0.07\% CX + 1\% cholesterol; CHO, cholesterol.

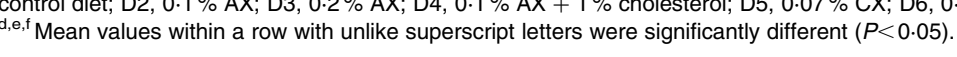


Table 6. Apparent digestibility coefficients (\%) of the seven experimental diets for DM, crude protein, carotenoids and energy

(Mean values with their standard errors of three replicates)

\begin{tabular}{|c|c|c|c|c|c|c|c|c|c|c|c|c|c|c|c|}
\hline \multirow[b]{3}{*}{ Digestibility } & \multicolumn{14}{|c|}{ Diets } & \multirow[b]{3}{*}{$P$} \\
\hline & \multicolumn{2}{|c|}{ D1 (control) } & \multicolumn{2}{|c|}{ D2 (AX-0.1) } & \multicolumn{2}{|c|}{ D3 (AX-0.2) } & \multicolumn{2}{|c|}{$\begin{array}{r}\text { D4 (AX-0.1 } \\
+ \text { CHO-1) }\end{array}$} & \multicolumn{2}{|c|}{ D5 (CX-0.07) } & \multicolumn{2}{|c|}{ D6 (CX-0.13) } & \multicolumn{2}{|c|}{$\begin{array}{c}\mathrm{D} 7(\mathrm{CX}-0.07 \\
+\mathrm{CHO}-1)\end{array}$} & \\
\hline & Mean & SE & Mean & SE & Mean & SE & Mean & SE & Mean & SE & Mean & SE & Mean & SE & \\
\hline Protein & $90 \cdot 4$ & 0.49 & $92 \cdot 2$ & 0.34 & $92 \cdot 0$ & 0.29 & $92 \cdot 1$ & 0.71 & $90 \cdot 4$ & 0.45 & $90 \cdot 2$ & 0.35 & $91 \cdot 2$ & 0.28 & 0.01 \\
\hline DM & $68 \cdot 8$ & 0.49 & $70 \cdot 4$ & 0.32 & $70 \cdot 7$ & 0.46 & $70 \cdot 9$ & 0.20 & $70 \cdot 8$ & 0.33 & $69 \cdot 6$ & 0.38 & $70 \cdot 6$ & 0.49 & 0.021 \\
\hline $\mathrm{AX}$ or $\mathrm{CX}$ & - & - & $98 \cdot 7^{\mathrm{C}}$ & 0.27 & $98 \cdot 8^{\mathrm{C}}$ & 0.32 & $99 \cdot 2^{\mathrm{C}}$ & 0.32 & $51 \cdot 3^{a}$ & 0.29 & $50 \cdot 4^{a}$ & 0.72 & $77 \cdot 4^{\mathrm{b}}$ & 0.24 & 0.000 \\
\hline Energy & 78.9 & 0.32 & $79 \cdot 8$ & 0.59 & $80 \cdot 2$ & 0.43 & $80 \cdot 1$ & 0.63 & 80.0 & 0.50 & $80 \cdot 8$ & 0.48 & $80 \cdot 1$ & 0.40 & 0.565 \\
\hline
\end{tabular}

D1, control diet; D2, 0.1\% astaxanthin; D3, 0.2\% astaxanthin; D4, 0.1\% astaxanthin $+1 \%$ cholesterol; D5, 0.07\% canthaxanthin; D6, 0.13\% canthaxanthin; D7, 0.07\% canthaxanthin $+1 \%$ cholesterol; $\mathrm{AX}$, astaxanthin; $\mathrm{CHO}$, cholesterol; CX, canthaxanthin.

${ }^{a, b, c}$ Mean values within a row with unlike superscript letters were significantly different $(P<0.05)$.

of canthaxanthin in the D5-D7 treatment $(P<0.05)$. The ADC of astaxanthin in the D2-D4 treatments were quite high $(>98 \%)$, and no differences were found among them $(P>0.05)$. The ADC of canthaxanthin in the D7 treatment was higher than that of canthaxanthin in the D5 and D6 treatments $(P<0.05)$.

\section{Haemolymph antioxidant enzyme activities}

Haemolymph antioxidant enzyme activities are shown in Table 7. The maximum TAS was observed in shrimp fed D4, which was different from those of shrimp fed the other diets $(P<0 \cdot 05)$. A significant increase in TAS was observed when the shrimp were fed the diets containing additional cholesterol (D4 v. D2 and D3, D7 v. D5 and D6).

The maximum SOD was observed in shrimp fed D1, which was different from those of shrimp fed the other diets $(P<0.05)$. SOD in shrimp fed the canthaxanthin-supplemented diets (D5-D7) was higher than that in shrimp fed the astaxanthin-supplemented diets (D2-D4) $(P<0.05)$.

Shrimp fed D1 and D5 showed higher AST than those fed D2-D4, D6 and D7 $(P<0 \cdot 05)$. No differences were found in AST among the shrimp fed D2-D4, D6 and D7 ( $P>0.05)$.

The maximum ALT was observed in shrimp fed D1, which was different from those of shrimp fed the other diets $(P<0 \cdot 05)$. No difference in ALT was found when shrimp fed the astaxanthin- or canthaxanthin-supplemented diets.

\section{Low dissolved oxygen stress tolerance test}

At the end of the stress tolerance test, survival of shrimp fed D1 was the lowest, as shown in Table 8. In addition, shrimp fed the diets containing astaxanthin or canthaxanthin showed no differences in survival during the first $6 \mathrm{~d}$ of the stress test $(P>0.05)$; however, the survival of shrimp fed D4 was significantly higher than that of shrimp fed D5 during the last day of the stress test.

\section{Discussion}

In the present study, the growth and survival of $P$. monodon were positively affected by the addition of carotenoids in their diet (Table 3); moreover, the body colour of the live shrimp fed D1 looked pale blue, while dark blue or dark brown was shown in shrimp fed the other diets supplemented with astaxanthin or canthaxanthin, and the colour of the live or boiled shrimp fed D4 was more intense than the others (Figs. 1 and 2). Segner et al. ${ }^{(37)}$ stated that carotenoids have a positive role in intermediary metabolism and had a beneficial effect on the growth of aquatic animals. Similarly, Amar et $a l .{ }^{(38)}$ and Niu et al. ${ }^{(4)}$ reported that dietary carotenoids, which serve as a pigment source, could also enhance nutrient utilisation and may ultimately result in improving the growth of aquatic animals. However, the effects of different dietary carotenoid sources on the growth and survival of aquatic organisms have been controversial. Chien \& Jeng ${ }^{(39)}$ reported a higher survival of $P$. japonicus fed astaxanthinsupplemented diets compared with shrimp fed $\beta$-carotene or algal meal-supplemented diets. In the study by Kim et al. ${ }^{(40)}$, the Korean rose bitterling (Rhodeus uyekii) fed an astaxanthin-supplemented diet showed higher growth than those fed lutein or $\beta$-carotene and control diets. In contrast, Boonyaratpalin et al. ${ }^{(9)}$ reported that the supplementation of a diet with $\beta$-carotene or astaxanthin had no significant effect on the growth, survival or FCR of $P$. monodon. As for the comparison of the effect of astaxanthin and canthaxanthin on the growth and survival of aquatic animals, Storebakken et $a l .{ }^{(41)}$ reported that astaxanthin is preferable to canthaxanthin because it produces nature-identical pigmentation and is more efficiently deposited. Yamada et al. ${ }^{(42)}$ also reported that astaxanthin was the most effective substance for pigmentation in prawn (P. japonicus) when compared with $\beta$-carotene and canthaxanthin. Kalinowski et al. ${ }^{(43)}$ evaluated the effect of supplementing a red porgy (Pagrus pagrus) diet with synthetic canthaxanthin or astaxanthin on growth and skin coloration. Their results showed that fish growth was not affected by the dietary carotenoid source; however, astaxanthin from the shrimp shell meal, particularly $40 \mathrm{mg} / \mathrm{kg}$ diet, gave the red porgy skin an overall reddish coloration, suggesting a better utilisation of astaxanthin than canthaxanthin. Similarly, the results of the present study also suggested that the inclusion of astaxanthin in the commercial diets of $P$. monodon significantly improved growth and skin coloration, and markedly enhanced the commercial value of this cultured species. 
The addition of cholesterol in the commercial diet of $P$. monodon significantly enhanced the positive effect of dietary astaxanthin and canthaxanthin. This enhanced positive effect was possibly due to the increasing levels of carotenoids found in the tissues (whole body, muscle, shell and plasma; Table 5). Moreover, the significantly high retention efficiencies of carotenoids and, accordingly, the high levels of carotenoids in the tissues (Tables 4 and 5) of the cholesterol-fed shrimp may possibly suggest that cholesterol could accelerate the deposition of the carotenoids in shrimp. Cholesterol as an ubiquitous major component of membranes (up to $25 \%$ in plasma membranes) determines the physical properties of native bilayers and of membrane-regulated processes ${ }^{(44)}$. The mechanism by which high dietary cholesterol increases the bioaccessibility of carotenoids in shrimp is unknown. As mentioned in the Introduction section, the concentration in bile lipids, which are assumed to be the only lipids that solubilise carotenoids in the aqueous phase of the intestinal lumen, may affect the transfer of carotenoids ${ }^{(23)}$. In the enterocyte, carotenoids are incorporated into chylomicrons, and due to the polarity of astaxanthin and canthaxanthin, it has been hypothesised that astaxanthin and canthaxanthin are surface-oriented $^{(45)}$. The chylomicrons are eventually delivered to the bloodstream and through the action of chylomicrons lose TAG content ${ }^{(45)}$. Although carotenoids are mainly carried by lipoproteins in the bloodstream, it is possible that non-TAG components of the chylomicron, including surface molecules such as astaxanthin and canthaxanthin, may be taken up by extrahepatic tissue or transferred to other lipoproteins in the bloodstream $^{(46)}$. Moreover, before hepatic uptake, chylomicrons in the bloodstream are rapidly degraded by lipoprotein lipase associated with tissue endothelium and transformed into chylomicron remnants ${ }^{(46)}$. Eventually, most chylomicron remnants deliver carotenoids to the liver where they are stored or resecreted into the bloodstream in $\mathrm{VLDL}^{(47)}$. apoB is the major structural protein of VLDL and chylomicrons, and cholesterol is an important determinant of apoB synthesis ${ }^{(48)}$. Furthermore, an increase in dietary cholesterol can also affect the cellular uptake and recycling of lipoproteins in the liver through the down-regulation of hepatic LDL-receptor activity ${ }^{(49)}$. Cholesterol and carotenoids have also been observed to compete for incorporation into liposomes ${ }^{(50)}$. Although cholesterol is favoured for incorporation due to its easy-to-fit structure compared with large carotenoid molecules, it must be considered that carotenoids are incorporated considerably into cell plasma membranes that need high cholesterol content and act as a barrier for the flow of carotenoids; moreover, penetration efficiency of carotenoids through plasma membranes is poor, and carriers are needed for penetration ${ }^{(51)}$. The close interaction of these lipid-soluble molecules in the gastrointestinal tract, enterocytes, plasma or tissues may also play a role in enhancing the absorption and deposition of carotenoids. Dietary cholesterol may promote the transport of carotenoids by increasing the formation of lipoprotein. Based on the above information, more work should be carried out to investigate the positive effect of dietary cholesterol on the bioaccessibility of carotenoids by increasing bile acid production or by regulating lipoprotein 
Table 8. Survival (\%) of ten shrimp fed the seven experimental diets during the $7 \mathrm{~d}$ stress tolerance test

(Mean values with their standard errors of three replicates)

\begin{tabular}{|c|c|c|c|c|c|c|c|c|c|c|c|c|c|c|c|}
\hline \multirow[b]{3}{*}{ Survival } & \multicolumn{14}{|c|}{ Diets } & \multirow[b]{3}{*}{$P$} \\
\hline & \multicolumn{2}{|c|}{ D1 (control) } & \multicolumn{2}{|c|}{ D2 (AX-0.1) } & \multicolumn{2}{|c|}{ D3 (AX-0.2) } & \multicolumn{2}{|c|}{$\begin{array}{r}\text { D4 (AX-0.1 } \\
+ \text { CHO-1) }\end{array}$} & \multicolumn{2}{|c|}{ D5 (CX-0.07) } & \multicolumn{2}{|c|}{ D6 (CX-0.13) } & \multicolumn{2}{|c|}{$\begin{array}{c}\text { D7 (CX-0.07 } \\
+ \text { CHO-1) }\end{array}$} & \\
\hline & Mean & SE & Mean & $\mathrm{SE}$ & Mean & SE & Mean & $\mathrm{SE}$ & Mean & SE & Mean & SE & Mean & SE & \\
\hline $1 d$ & 100 & 0.0 & 100 & 0.0 & 100 & 0.0 & 100 & 0.0 & 100 & 0.0 & 100 & 0.0 & 100 & 0.0 & \\
\hline $2 d$ & $86 \cdot 7^{a}$ & $6 \cdot 7$ & $96 \cdot 7^{a, b}$ & 3.3 & $100^{\mathrm{b}}$ & 0.0 & $100^{\mathrm{b}}$ & 0.0 & $96 \cdot 7^{a, b}$ & 3.3 & $93 \cdot 3^{a, b}$ & 3.3 & $100^{\mathrm{b}}$ & 0.0 & 0.113 \\
\hline $3 d$ & $70 \cdot 0^{a}$ & $5 \cdot 8$ & $93 \cdot 3^{\mathrm{b}}$ & 3.3 & $100^{b}$ & 0.0 & $100^{\mathrm{b}}$ & 0.0 & $93 \cdot 3^{\mathrm{b}}$ & 3.3 & $90 \cdot 0^{\mathrm{b}}$ & $5 \cdot 8$ & $93 \cdot 3^{b}$ & 3.3 & 0.001 \\
\hline $4 d$ & $50.0^{\mathrm{a}}$ & 5.8 & $90.0^{\mathrm{b}}$ & $5 \cdot 8$ & $96 \cdot 7^{\mathrm{b}}$ & $3 \cdot 3$ & $100^{\mathrm{b}}$ & 0.0 & $90 \cdot 0^{\mathrm{b}}$ & $5 \cdot 8$ & $86 \cdot 7^{\mathrm{b}}$ & 6.7 & $90 \cdot 0^{\mathrm{b}}$ & $5 \cdot 8$ & 0.000 \\
\hline $5 d$ & $30 \cdot 0^{\mathrm{a}}$ & 5.8 & $90.0^{\mathrm{b}}$ & $5 \cdot 8$ & $90 \cdot 0^{\mathrm{b}}$ & $5 \cdot 8$ & $96 \cdot 7^{b}$ & 3.3 & $83 \cdot 3^{\mathrm{b}}$ & 8.0 & $83 \cdot 3^{\mathrm{b}}$ & 3.3 & $86 \cdot 7^{\mathrm{b}}$ & 6.7 & 0.000 \\
\hline $6 d$ & $23 \cdot 3^{a}$ & 3.3 & $86 \cdot 7^{b}$ & 6.7 & $90 \cdot 0^{b}$ & 5.8 & $93 \cdot 3^{\mathrm{b}}$ & $6 \cdot 7$ & $76 \cdot 7^{\mathrm{b}}$ & $8 \cdot 8$ & $80 \cdot 0^{\mathrm{b}}$ & 0.0 & $86 \cdot 7^{\mathrm{b}}$ & $6 \cdot 7$ & 0.000 \\
\hline $7 d$ & $13 \cdot 3^{a}$ & 8.8 & $76 \cdot 7^{\mathrm{b}, \mathrm{c}}$ & 3.3 & $83 \cdot 3^{b, c}$ & 3.3 & $93 \cdot 3^{\mathrm{C}}$ & $6 \cdot 7$ & $70 \cdot 0^{\mathrm{b}}$ & $5 \cdot 8$ & $76 \cdot 7^{\mathrm{b}, \mathrm{c}}$ & 3.3 & $86 \cdot 7^{\mathrm{b}, \mathrm{c}}$ & 6.7 & 0.000 \\
\hline
\end{tabular}

D1, control diet; D2, $0.1 \%$ astaxanthin; D3, 0.2\% astaxanthin; D4, 0.1\% astaxanthin $+1 \%$ cholesterol; D5, 0.07\% canthaxanthin; D6, 0.13\% canthaxanthin; D7, 0.07\% canthaxanthin $+1 \%$ cholesterol; $\mathrm{AX}$, astaxanthin; $\mathrm{CHO}$, cholesterol; $\mathrm{CX}$, canthaxanthin.

${ }_{\mathrm{a}, \mathrm{b}, \mathrm{c}}$ Mean values within a row with unlike superscript letters were significantly different $(P<0.05)$.

synthesis. It is also important to understand more fully the kinetics of absorption, transport, metabolism and tissue uptake of carotenoids.

In the present investigation, no differences $(P>0.05)$ were recorded in the ADC of protein, DM and energy among all the experimental diets for juvenile P. monodon (Table 6). The ADC of astaxanthin in the experimental diets were quite high $(>98 \%)$, and no differences were found among the three astaxanthin-supplemented diets (D2-D4). Moreover, the addition of dietary cholesterol significantly improved canthaxanthin digestibility from 50 to $77 \%$ for $P$. monodon. The ADC of astaxanthin for $P$. monodon was significantly higher than that for fish. The ADC of astaxanthin for rainbow trout (O. mykiss) and Atlantic salmon (S. salar L.) were in the range of $50-70^{(52,53)}$ and $59-64 \%^{(54)}$, respectively. Though the present results showed that astaxanthin digestibility for P. monodon was quite high (Table 6), however, the carotenoid retention efficiency in the tissues of $P$. monodon was considerably low (Table 4). This means that dietary astaxanthin could be digested effectively in the gastrointestinal tract of P. monodon, but as a result, could not be deposited in tissues for pigmentation. The low degree of retention efficiency may partly be due to a low incorporation of carotenoids into chylomicrons, a low secretion of carotenoids and their metabolites associated with chylomicrons into the lymph, or metabolic transformation into colourless compounds that may eventually be excreted ${ }^{(24)}$. However, the mechanisms of carotenoid action in shrimp are still unclear. Information is needed regarding the efficiency of astaxanthin and canthaxanthin absorption, intracellular factors regulating the process of their absorption, the mechanism of intracellular transport of these carotenoids and their incorporation into chylomicrons, and the interactions between carotenoids and other dietary factors (such as cholesterol in the present experiment) during lipoprotein transportation and tissue deposition. A factorial design using an in vitro model is being applied to identify the main factors affecting transportation and deposition, which are currently under investigation.

Enhancement of resistance in penaeid shrimp to oxygen depletion stress $^{(4,55)}$ (also in the present study), salinity stress ${ }^{(1)}$, thermal stress ${ }^{(1)}$ and $\mathrm{NH}_{3}$ stress $^{(7)}$ was found to be associated with dietary carotenoids. In the present experiment, shrimp fed the diet supplemented without carotenoids (D1) exhibited significantly poorer resistance to low DO stress under our conditions compared with shrimp fed with the carotenoid-supplemented diets (D2-D7) during the stress tolerance test $(P<0.05)$ (Table 8). Similar results have also been reported by Chien et al. ${ }^{(55)}$ and Niu et al. ${ }^{(4)}$. Oxygen-containing carotenoids such as astaxanthin ${ }^{(56)}$, in which oxygen is attached at the centre of the hydrocarbon chain $^{(49)}$, may serve as an intracellular oxygen supply for shrimp, allowing survival and prolonging the life of shrimp under hypoxic conditions ${ }^{(39)}$. Aside from being active in serving as oxygen reservoirs in the neuronal respiratory chain, dietary carotenoids also proved to influence cellular activities and to act as protective (mainly antioxidant) agents to protect sensitive tissues and reactive compounds from damage due to oxidation ${ }^{(57,58)}$. This can be seen from the antioxidant capacity of $P$. monodon (Table 7).

TAS is an overall indicator of the antioxidant status of an individual. As the value increases, the antioxidant defence against the free radical reaction increases ${ }^{(1)}$. SOD is a major antioxidant enzyme, which is responsible for scavenging reactive oxygen species and protecting mechanisms within tissue injury following the radical process and phagocytosis ${ }^{(7)}$ In the present study, when compared with shrimp fed the diet supplemented without carotenoids (D1), SOD in shrimp fed with the carotenoid-supplemented diets (D2-D7) remained relatively low and constant, and TAS increased gradually but stayed high as dietary carotenoids increased; moreover, the additional supplementation of dietary cholesterol significantly increased TAS on the basis of the original. The present results showed that body carotenoids improved TAS, enhanced resistance against low DO stress and reflected higher survival in shrimp; the higher the SOD value is, the more superoxide radicals need to be reacted. LOw SOD and high TAS favoured shrimp survival as reflected in the present low DO stress tolerance test. On the other hand, astaxanthin, which has strong oxygen-quenching activities, has been suggested to play a role in protecting marine organisms from reactive oxygen species ${ }^{(59)}$. 
AST and ALT were directly or indirectly related to oxidant metabolites so that they could serve as indicators of oxidative status $^{(1)}$. In the present study, shrimp fed with the carotenoidsupplemented diets (D2-D7) had their AST and ALT always lower than shrimp fed the diet supplemented without carotenoids (D1). Nakano et al. ${ }^{(60)}$ reported that AST activities of rainbow trout (O. mykiss) fed a diet containing astaxanthin were significantly lower than those of the control fish. Further study by Nakano et al. ${ }^{(61)}$ indicated that rainbow trout (O. mykiss) fed a diet containing red yeast, Phaffia rbodozyma, which is rich in astaxanthin, decreased serum ALT and AST considerably. Pan et al. ${ }^{(7)}$ reported that shrimp fed an astaxanthin-containing diet had AST always lower than the control shrimp and ALT lower than or equal to the control shrimp. Chien et al. ${ }^{(1)}$ also reported the positive effect of astaxanthin on the hepatopancreas of juvenile $P$. monodon, indicating the lowering of either AST or ALT under osmotic or thermal stress, respectively. The enhancement of antioxidation capacity by dietary carotenoids, and consequently, the improvement of survival against low DO stress, suggests that for P. monodon, dietary carotenoids, especially astaxanthin, are a survival enhancer, which can become critical particularly when shrimp is under low DO stress.

\section{Acknowledgements}

This study was supported by the National Natural Science Foundation of China (31101911/C190401), and the Central Institutes of Public Welfare Projects (2009TS29 and 2010YD02), and the Key Lab of Freshwater Ecology and Healthy Aquaculture, CAFS (no. 2010FEA03007) and the Special Fund of Marine Fisheries Science and Technology, Guangdong Province (A200901B02 and A201001B01). The authors thank the participants who gave their time to this trial. J. N., C.-H. L., Y.-J. L., L.-X. T. and H.-Z. L. designed the study. X. C. and Z. H. carried out the rearing experiments. J. N. analysed the results and wrote the manuscript with contributions from the other authors. There are no conflicts of interest.

\section{References}

1. Chien $\mathrm{YH}$, Pan $\mathrm{CH} \&$ Hunter B (2003) The resistance to physical stresses by Penaeus monodon juveniles fed diets supplemented with astaxanthin. Aquaculture 216, 177-191.

2. Supamattaya $\mathrm{K}$, Kiriratnikom S, Boonyaratpalin $\mathrm{M}$, et al. (2005) Effect of a Dunaliella extract on growth performance, health condition, immune response and disease resistance in black tiger shrimp (Penaeus monodon). Aquaculture 248, 207-216

3. Paibulkichakul C, Piyatiratitivorakul S, Sorgeloos $\mathrm{P}$, et al. (2008) Improved maturation of pond-reared, black tiger shrimp (Penaeus monodon) using fish oil and astaxanthin feed supplements. Aquaculture 282, 83-89.

4. Niu J, Tian LX, Liu YJ, et al. (2009) Effect of dietary astaxanthin on growth, survival and stress tolerance of postlarval shrimp, Litopenaeus vannamei. J World Aquacul Soc $\mathbf{4 0}$, 795-802.

5. Chien YH \& Shiau WC (2005) The effects of dietary supplementation of algae and synthetic astaxanthin on body astaxanthin, survival, growth, and low dissolved oxygen stress resistance of kuruma prawn, Marsupenaeus japonicus Bate. J Exp Mar Biol Ecol 318, 201-211.

6. Niu J, Tian LX, Lin HZ, et al. (2011) Carotenoids in aquaculture - an overview. J Anim Sci Biotech 2, 44-58.

7. Pan $\mathrm{CH}$, Chien $\mathrm{YH} \&$ Hunter B (2003a) The resistance to ammonia stress of Penaeus monodon Fabricius juvenile fed diets supplemented with astaxanthin. J Exp Mar Biol Ecol 297, 107-118.

8. Pan CH, Chien YH \& Hunter B (2003) Alterations of antioxidant capacity and hepatopancreatic enzymes in Penaeus monodon (Fabricius) juveniles fed diets supplemented with astaxanthin and exposed to Vibrio damsela challenge. J Fish Soc Taiwan 30, 279-290.

9. Boonyaratpalin M, Thongrod S, Supamattaya K, et al. (2001) Effects of $\beta$-carotene source, Dunaliella salina, and astaxanthin on pigmentation, growth, survival and health of Penaeus monodon. Aquac Res 32, 182-190.

10. Okada S, Nur-E-Borhan SA \& Yamaguchi K (1994) Carotenoid composition in the exoskeleton of commercial black tiger prawns. Fish Sci 60, 213-215.

11. Barbosa MJ, Morais R \& Choubert G (1999) Effect of carotenoid source and dietary lipid content on blood astaxanthin concentration in rainbow trout (Oncorbynchus mykiss). Aquaculture 176, 331-341.

12. Buttle LG, Crampton VO \& Williams PD (2001) The effect of feed pigment type on flesh pigment deposition and colour in farmed Atlantic salmon, Salmo salar L.. Aquac Res 32, $103-111$.

13. Kiessling A, Olsen RE \& Buttle L (2003) Given the same dietary carotenoid inclusion, Atlantic salmon, Salmo salar (L) display higher blood levels of canthaxanthin and astaxanthin. Aquacult Nutr 9, 253-261.

14. Choubert G, Gómez R \& Milicua JCG (1994) Response of serum carotenoid levels to dietary astaxanthin and canthaxanthin in immature rainbow trout Oncorbynchus mykiss. Comp Biochem Physiol 109A, 1001-1006.

15. Nickell DC \& Bromage NR (1998) The effect of timing and duration of feeding astaxanthin on the development and variation of fillet colour and efficiency of pigmentation in rainbow trout (Oncorbynchus mykiss). Aquaculture 169, $233-246$.

16. Bjerkeng B, Hatlen B \& Jobling M (2000) Astaxanthin and its metabolites idoxanthin and crustaxanthin in flesh, skin, and gonads of sexually immature and maturing Arctic charr (Salvelinus alpinus (L.)). Comp Biochem Physiol 125B, 395-404.

17. Regost C, Jakobsen JV \& Rørå AMB (2004) Flesh quality of raw and smoked fillets of Atlantic salmon as influenced by dietary oil sources and frozen storage. Food Res Int 37, 259-271.

18. Bjerkeng B, Hatlen B \& Wathne E (1999) Deposition of astaxanthin in fillets of Atlantic salmon (Salmo salar) fed diets with herring, capelin, sandeel, or Peruvian high PUFA oils. Aquaculture 180, 307-319.

19. Bell JG, McEvoy J, Tocher DR, et al. (2001) Replacement of fish oil with rapeseed oil in diets of Atlantic salmon (Salmo salar) affects tissue lipid compositions and hepatocyte fatty acid metabolism. J Nutr 131, 1535-1543.

20. Bell JG, Henderson RJ, Tocher DR, et al. (2002) Substituting fish oil with palm oil in the diet of Atlantic salmon (Salmo salar) affects muscle fatty acid compositions and hepatic fatty acid metabolism. J Nutr 131, 222-230.

21. Salvador AM, Alonso-Damián A, Choubert G, et al. (2009) Impact of different dietary phospholipid levels on cholesterol and canthaxanthin lipoprotein-serum transport and muscle deposition in rainbow trout. J Agr Food Chem 57, 2016-2021.

22. Yeum KJ \& Russell RM (2002) Carotenoid bioavailability and bioconversion. Annu Rev Nutr 22, 483-504. 
23. Tyssandier V, Lyan B \& Borel P (2001) Main factors governing the transfer of carotenoids from emulsion lipid droplets to micelles. Biochem Biophys Acta 1533, 285-292.

24. van Het Hof KH, West CE, Weststrate JA, et al. (2000) Dietary factors that affect the bioavailability of carotenoids. $J$ Nutr 130, 503-506.

25. O'doherty PJA, Kakis G \& Kuksis A (1973) Role of luminal lecithin in intestinal absorption. Lipid 8, 241-328.

26. Horton JD, Cuthbert JA \& Spady DK (1995) Regulation of 7 alpha-hydroxylase expression and response to dietary cholesterol in the rat and hamster. J Biol Chem 270, 5381-5387.

27. Lakshman MR, Liu QH, Spaa M, et al. (1996) The effect of dietary taurocholate, fat, protein and carbohydrate on the distribution and fate of dietary $\beta$-carotene in ferrets. Nutr Cancer 26, 49-61.

28. Schweigert FJ, Trupschuch A \& Hantschel C (2002) Modulation of absorption of beta-carotene and tissue accumulation of beta-carotene and vitamin A by different surfactants in rats. Ann Nutr Metab 46, 200-204.

29. Shiau SY, Lin SF \& Lu LJ (1991) Effects of different types of wheat flour in feed for grass prawn Penaeus monodon. Nippon Suisan Gakk 57, 705-710.

30. Merican ZO \& Shim KF (1995) Apparent digestibility of lipid and fatty acids in residual lipids of meals by adult Penaeus monodon. Aquaculture 133, 275-286.

31. Association of Official Analytical Chemists (AOAC) (1984) Official Methods of Analysis, 14th ed. Arlington, VA: AOAC.

32. Refstie S, Helland SJ \& Storebakken T (1997) Adaptation to soybean meal in diets for rainbow trout (Oncorbynchus mykiss). Aquaculture 153, 263-272.

33. Schierle J \& Hardi W (1994) Determination of stabilised astaxanthin in Carophyll ${ }^{\circledR}$ Pink, premixes and fish feeds. In Analytical Methods for Vitamins and Carotenoids in Feed, pp. 59-61 [P Hoffmann, HE Keller, J Schierle and W Schuep, editors]. Basel: Roche.

34. Schiedt K, Bischof S \& Glinz E (1995) Example 5: fish. Isolation of astaxanthin and its metabolites from skin of Atlantic salmon (Salmo salar). In Carotenoids 1A: Isolation and Analysis, pp. 243-252 [G Britton, S Liaaen-Jensen and $\mathrm{H}$ Pfander, editors]. Basel: Birkhäuser.

35. Weber S (1988) Determination of stabilised, added astaxanthin in fish feeds and premixes with HPLC. In Analytical Methods for Vitamins and Carotenoids in Feeds, pp. 59-61 [HE Keller, editor]. Publication No. 2264. Basel: Roche.

36. Pan CH, Chien YH \& Cheng JH (1999) Carotenoid content in various tissues of cultured Penaeus monodon by their sizes, sexes, and molting stages. J Fish Soc Taiwan 26, 51-57.

37. Segner H, Arend P, Poeppinghausen K, et al. (1989) The effect of feeding astaxanthin to Oreochromis niloticus and Colisa labiosa on the histology of the liver. Aquaculture 79, 381-390.

38. Amar EC, Kiron V, Satoh S, et al. (2001) Influence of various dietary synthetic carotenoids on bio-defence mechanisms in rainbow trout, Oncorbynchus mykiss (Walbaum). Aquac Res 32, 162-173.

39. Chien YH \& Jeng SC (1992) Pigmentation of kuruma prawn, Penaeus japonicus Bate, by various pigment sources and levels and feeding regimes. Aquaculture 102, 333-346.

40. Kim HS, Kim YH, Cho SH, et al. (1999) Effects of dietary carotenoids on the nuptial color of the bitterling (Rhodeus uyekii). J Korean Fish Soc 32, 276-279.

41. Storebakken T, Foss P, Austreng E, et al. (1987) Carotenoids in diets for salmonids: IV. Pigmentation of Atlantic salmon with astaxanthin, astaxanthin-dipalmitate and canthaxanthin. Aquaculture 65, 279-292.

42. Yamada S, Tanaka Y, Sameshima M, et al. (1990) Pigmentation of prawn (Penaeus japonicus) with carotenoids: I. Effect of dietary astaxanthin, $\beta$-carotene and canthaxanthin on pigmentation. Aquaculture 87, 323-330.

43. Kalinowski CT, Robaina LE, Fernández-Palacios H, et al (2005) Effect of different carotenoid sources and their dietary levels on red porgy (Pagrus pagrus) growth and skin colour. Aquaculture 244, 223-231.

44. Härtel S, Diehl HA \& Ojeda F (1998) Methyl-beta-cyclodextrins and liposomes as water-soluble carriers for cholesterol incorporation into membranes and its evaluation by a microenzymatic fluorescence assay and membrane fluidity-sensitive dyes. Anal Biochem 258, 277-284.

45. Parker RS (1996) Absorption, metabolism, and transport of carotenoids. FASEB J 10, 542-551.

46. Deming DM \& Erdman JW Jr (1999) Mammalian carotenoid absorption and metabolism. Pure Appl Chem 71, 2213-2223.

47. Herbeth B, Gueguen S, Leroy P, et al. (2007) The lipoprotein lipase serine 447 stop polymorphism is associated with altered serum carotenoid concentrations in the stanislas family study. J Am Coll Nutr 26, 655-662.

48. Kumar NS, Abraham R, Kumar GS, et al. (1992) Synthesis and secretion of VLDL by rat hepatocytes-modulation by cholesterol and phospholipids. Indian J Biochem Biophys 29, 438-441.

49. Karnaukhov VN (1979) The role of filtrator mollusks rich in carotenoid in the self-cleaning of fresh waters. Symp Biol Hung 19, 151-167.

50. Grolier P, Azais-Braesco V, Zelmire L, et al. (1992) Incorporation of carotenoidystems: uptake by cultured rat hepatocytes. Biochim Biophys Acta 1111, 135-138.

51. Socaciu C, Lausch C \& Diehl HA (1999) Carotenoids in DPPC vesicles: membrane dynamics. Spectrochim Acta 55A, 2289-2297.

52. Bjerkeng B, Følling M, Lagocki S, et al. (1997) Bioavailability of all- $E$-astaxanthin and $Z$-astaxanthin isomers in rainbow trout (Oncorhynchus mykiss). Aquaculture 157, 63-82.

53. White DA, Ørnsrud R \& Davies SJ (2003) Determination of carotenoid and vitamin A concentrations in everted salmonid intestine following exposure to solutions of carotenoid in vitro. Comp Biochem Physiol 136A, 683-692.

54. Bjerkeng B \& Berge GM (2000) Apparent digestibility coefficients and accumulation of astaxanthin $E / Z$ isomers in Atlantic salmon (Salmo salar L.) and Atlantic halibut (Hippoglossus hippoglossus L.). Comp Biochem Physiol 127B, 423-432.

55. Chien YH, Chen IM, Pan CH, et al. (1999) Oxygen depletion stress on mortality and lethal course of juvenile tiger prawn Penaeus monodon fed high level of dietary astaxanthin. J Fish Soc Taiwan 26, 85-93.

56. Czeczuga B (1979) Carotenoids in fish: XIX. Carotenoids in the eggs of Oncorbynchus keta. Hydrobiologia 63, 45-47.

57. Shaish A, Daugherty A, O'Sullivan F, et al. (1995) Betacarotene inhibits atherosclerosis in hypercholesterolemic rabbits. J Clin Invest 96, 2075-2082.

58. Lazrak T, Milon A, Wolff G, et al. (1996) Beta-carotene, carotenoids and disease prevention in humans. FASEB $J$ 10, 690-701.

59. Shimidzu N, Goto M \& Miki W (1996) Carotenoids as singlet oxygen quenchers in marine organisms. Fish Sci 62, 134-137.

60. Nakano T, Tosa M \& Takeuchi M (1995) Improvement of biochemical features in fish health by red yeast and synthetic astaxanthin. J Agric Food Chem 43, 1570-1573.

61. Nakano T, Kanmuri T, Sato M, et al. (1999) Effect of astaxanthin rich red yeast (Phaffia rhodozyma) on oxidative stress in rainbow trout. Biochim Biophys Acta 1426, 119-125.

62. Bautista-Teruel MN, Eusebio PS \& Welsh TP (2003) Utilization of feed pea, Pisum sativum, meal as a protein source in practical diets for juvenile tiger shrimp, Penaeus monodon. Aquaculture 225, 121-131. 